ISSN: 1812-1217

E- ISSN: 1998-0345

\title{
Challenge Skills Criteria for Dental Implants Success in Inferior Alveolar Nerve Lateralization and Transposition
}

Dr.Rawaa Y. Al-Rawee BDS. MSc, OS.PhD, MOMS MFDS RCPSG

\section{Dr.Bashar Abdul-Ghani Tawfeeq BDS. FICMS.}

\section{Dr. Radhwan H. Alkhashab MBChB , FIBMS}

Department of Oral and Maxillofacial Surgery

Nineveh Health Directorate, Ministry of Health. Iraq

\section{Department Of Oral And Maxillofacial Surgery}

Nineveh Health Directorate, Ministry of Health. Iraq

Department of Anesthesia and Intensive care unit Nineveh Health Directorate, Ministry of Health. Iraq

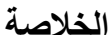

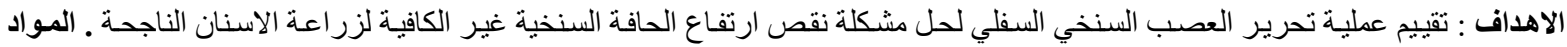

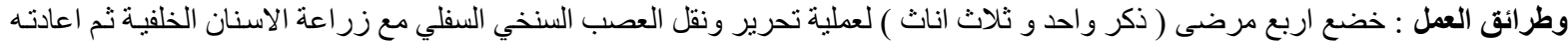

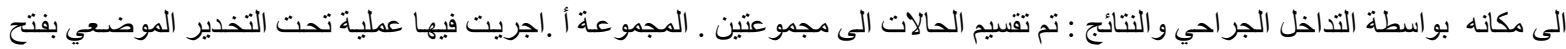

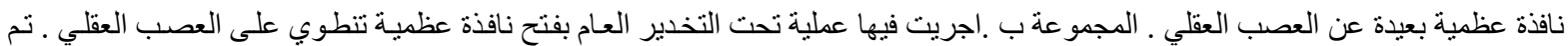

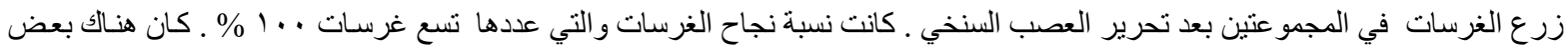

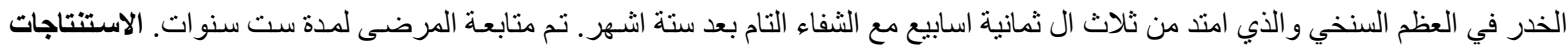

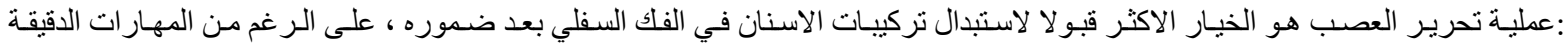
و التحديات يجب ان تكون متاحة للجر اح من اجل تحقيق نتائج افضل على لألى المدى البعيد ....
\end{abstract}

\begin{abstract}
Aims: Evaluate the surgical procedure of inferior alveolar nerve (IAN) freeing to solve the problem of insufficient posterior alveolar ridge height for successful dental implant insertion. Materials and Methods Case series: Four patients underwent inferior alveolar nerve translocation operation with dental implant, one male and 3 female. Intervention and outcome: Cases were divided to 2 groups, group A in which surgery was conducted under local anesthesia were the bony windows not involve the mental nerve, the window done distal to mental nerve. Group B where surgery was conducted under general anesthesia with bony window involve mental nerve. Result: A total of 9 dental implants were successfully inserted following translocation of the inferior alveolar nerve. Fixed prosthesis was delivered with satisfactory feedback from patients. Accompanying paresthesia extended between 3 to 8 weeks with complete recovery after 6 months. Patients followed for 6 years with periodic visits or phone call each 6 months. Conclusion: IAN Lateralization and Transposition is appropriate choice for dental implant replacement in atrophied posterior mandible. Skill, precise and experience challenges of surgeons are mandatory for optimal and long term success result. Permanent injury to the IAN should be avoided by accurate clinical and radiographical examination. Patient preference for local or general anesthesia has no effect on surgeries itself.
\end{abstract}

Key words: Inferior alveolar nerve, Implant, Mental foramen, Parasthesia..

Al-Rawee RY., Tawfeeq BA, Alkhashab RH. Challenge Skills Criteria for Dental Implants Success in Inferior Alveolar Nerve Lateralization and Transposition .Al-Rafidain Dent J. 2020;20(1):25-35.

DOI: $10.33899 /$ rden.2020.164518

Received: 23/1/2020 Sent to Referees: 25/1/2020 Accepted for Publication: 26/4 /2020 


\section{INTRODUCTION}

Inadequate bone height in the edentulous posterior mandible is one of critical complications that can face an implantologist. Inferior alveolar nerve (IAN) translocation considers as an important solution for patients with such problem. Rehabilitation of the atrophied posterior mandibular region poses a challenge difficulties for dental team and to some extent for professionals as the surgical procedure subjected to anatomical, surgical and biological difficulties ${ }^{(1)}$. Other solutions for atrophied mandibular posterior region include using short implants, vertical bone graft also bypass implants and distracters.

To avoid vertical bone augmentation for cases of atrophic bone, IAN Lateralization (IANL) and IANT Transposition (IANT) surgical procedures can be used to reposition the IAN before implant placement.

In the IANL surgical procedure, lateral reflection of the IAN without incisive nerve traction is performed preserving the mental nerve with lateralization of the inferior alveolar neurovascular bundle posterior to the mental foramen. ${ }^{(2)}$ IANT procedure, a corticotomy is done by change position of the mental foramen itself so transposition the incisive and the IAN such that the mental foramen positioned more posteriorly. In 1987, Jensen and Nock were the first to publish this technique developed for the translocation of the mental foramen ${ }^{(2)}$.In such cases surgeon skill is mandatory for inferior alveolar nerve (IAN) preservation in a mandibular surgery ${ }^{(3)}$. The advantages for such approaches are to locate the dental implants in an ideal position that can provide high success rate supporting fixed restorative prosthesis. Numbness and paresthesia may follow surgery which needs need special attention. Surgeon skill, accuracy, focuses and quietness is essential when preparing the osteotomy and manipulation of the IAN in sequence reduce complications (4.5.6.). IAN Manipulation surgery can be used in the following: mandibular sub-apical osteotomy in orthognathic surgery cases ${ }^{(7,8)}$. Pre-prosthetic surgery ${ }^{(9)}$. Atrophied posterior mandible in implant surgeries $(10,11)$. Disrupted IAN anastomosis ${ }^{(12)}$ and cancer surgery was IAN preservation is needed ${ }^{(13)}$.

Objectives: Highlighting how to confront clinical scenarios with insufficient posterior alveolar ridge height prior to instillation of dental implants. In this clinical study, cases are presented with different surgical approaches for IAN manipulation before implant placement with follow-up.

Ethical Approval: Human Ethical Scientific Approval Application Form for Research is organized following the recommendation of the scientific committee of the Nineveh Health Directory / Ministry of Health / Iraq. License No. 189 in 7/10/2019. The article ID. (19/123) 


\section{MATERIALS AND METHODS}

Case Presentation: Out of three hundred patients whom attended the dental implant unit in the maxillofacial section at Al-Salam Teaching Hospital / Nineveh Health Directorate / Mosul / Iraq; only four patients were enrolled in this clinical study and whom underwent inferior alveolar nerve surgery in a one year period $1 / 1 / 2010$ - 1/1/2011. The same preparation protocol was followed for the four patients including accurate clinical and radiographical examinations. A special case sheet was designed within included necessary details to be read by each patient to be enrolled explaining its possible risks and signed (Informed Consent). The surgical procedure was discussed thoroughly between the surgeon and patient. A standard surgical protocol and dental implant instillation was followed. Type of anesthesia to be used was operation difficulty based.

First Case: Fifty five years old female present with history of previous dental implant in our center with an edentulous left posterior ridge (lost premolars and molars). Orthopantomography (OPG) showed a resorbed alveolar ridge in sufficient to accommodate proper implant height (available height from the crest of the ridge to the superior line of the inferior alveolar canal was $6 \mathrm{~mm}$ ). The treatment plan explained for IAN translocation (Table 1, Figure 1). The patient prepared to be operated under local anesthesia (LA).

Table 1: Descriptions of cases

\begin{tabular}{cccccc}
\hline & Age & Surgical tech & Anesthesia & Parasth. P. & Survival rate \\
\hline Group A & 55 & $*$ M.N. not I. & Local & 8 weeks & $100 \%$ \\
Group A & 45 & $*$ M.N. not I. & Local & 3 weeks & $100 \%$ \\
Group B & 42 & $* *$ M.N I. & General & 3 weeks & $100 \%$ \\
Group B & 57 & $* *$ M.N. I. & General & 5 weeks & $100 \%$ \\
\hline
\end{tabular}

*M.N. not I= Mental Nerve Not Involved

**M.N.I.= Mental Nerve Involved
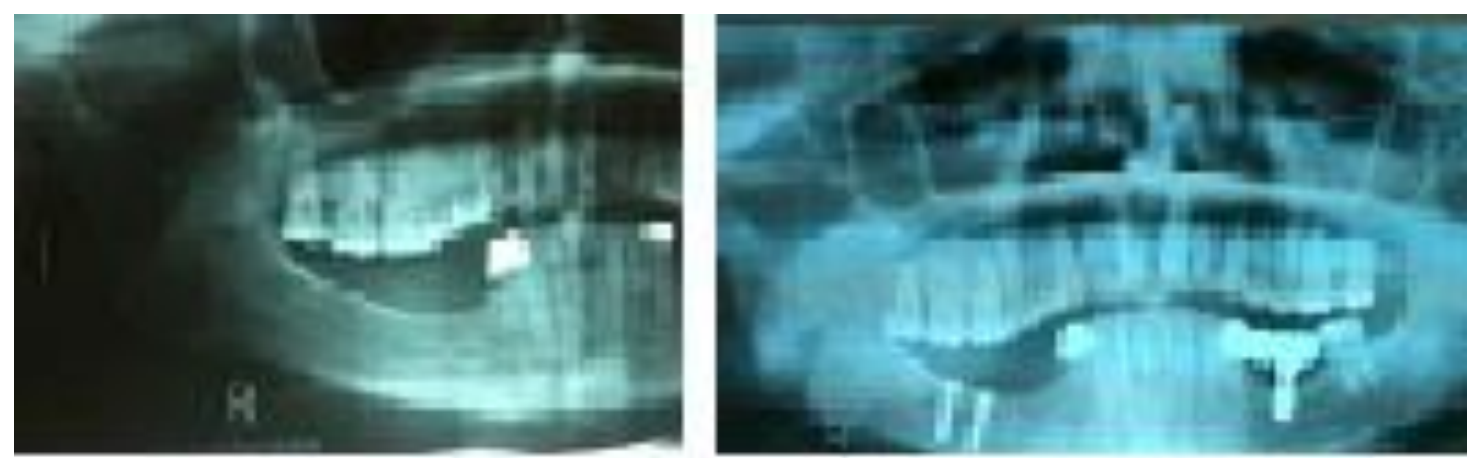

Figure 1:1st Case Pre and Post Radiographs (OPG) 
Second case: A 45 year old female in which examination revealed loss of lower right $2^{\text {nd }}$ premolar, $1^{\text {st }}$ and $2^{\text {nd }}$ molars.

Orthopantomography showed insufficient alveolus height. (5mm), patient prepared for operation under LA (Table 1, Figure 2).
Third case: A 42 year old female, with an edentulous bilateral posterior ridge in the premolar and molar area. The radiograph showed a severe resorbed alveolar ridge which was not enough to accommodate dental implants ( $4 \mathrm{~mm}$ height). The operation decided to be done under general anesthesia (Table, Figure3).
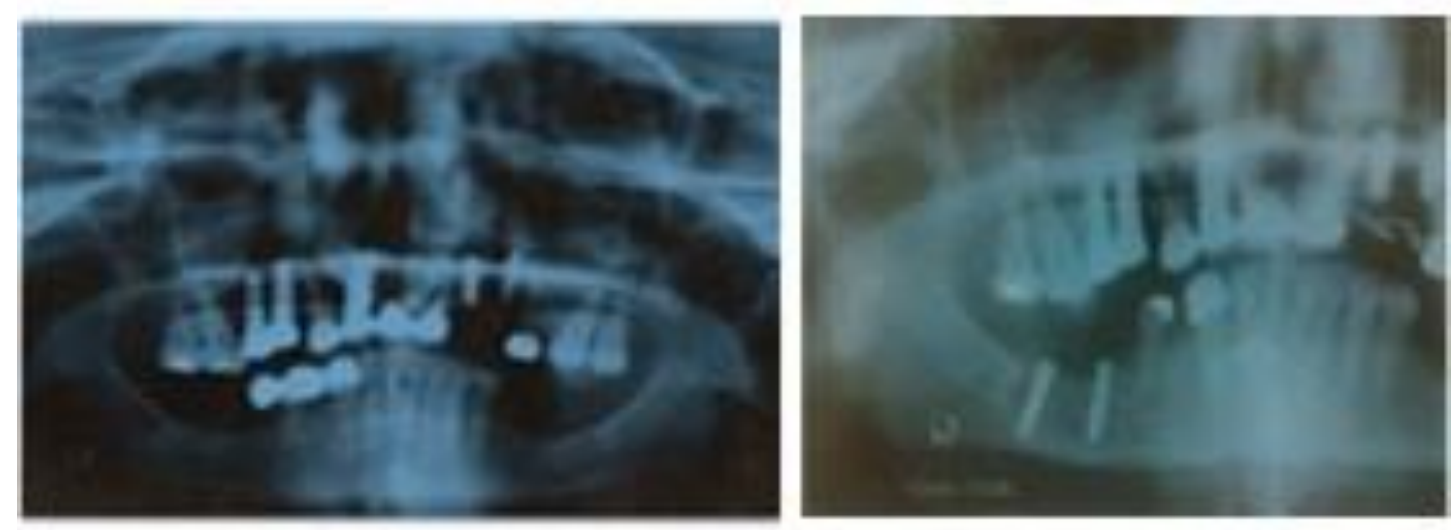

Figure 2: 2nd case Pre and Post Radiographs (OPG)
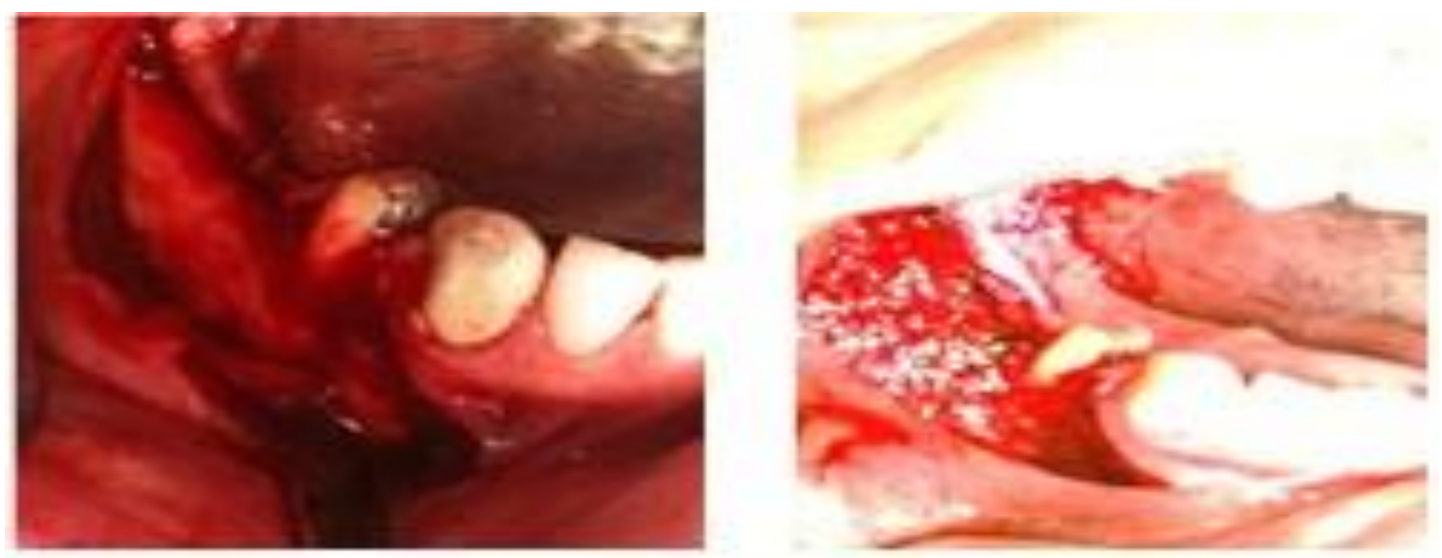

Figure 3: Surgical approach involves the mental nerve

Fourth case: A 57 year old male. Examination revealed a completely edentulous maxilla with an edentulous lower right posterior ridge in the premolar and molar region. Orthopantomography showed a resorbed alveolar ridge which was not enough to accommodate dental implants $(5 \mathrm{~mm}$ height only). So we discuss the treatment plan with 
the patient to be done under general anesthesia.

Interventions and Outcome: The choice of surgical technique whether lateralization or transposition of the IAN depends on mental nerve involvement during surgery ${ }^{(10) .}$ In this study, the mental foramen was either involved in the bony window for exploration of the nerve or the bony window made being distal to the mental foramen. The site of osteotomies performed was based on calculating the distance between alveolar ridge and the IAN canal. In the first and second patient, osteotomy was performed (Figure 1) distal to mental foramen (lateralization) under local anesthesia (group A) while for the third and fourth patient, osteotomy involved the mental foramen in its bony window (transposition) under general anesthesia (group B) (Figure 2) / Table (1). All patients were closely observed following surgery during the first 2 months. Each surgery involved accurate elevation of a three sided mucoperiosteal flap (crestal incision with horizontal incisions starting mesial to the canine tooth) and identification of the mental foramen both radiographically and clinically.

Bony osteotomies: A bony window osteotomy in group A (Figure 4) was made posterior to the mental foramen about $2 \times 1 \mathrm{~cm}$, leaving a 3-4 $\mathrm{mm}$ distance from the crest of the ridge. In group B (Figure 3), the bony window involved the mental foramen, this being more accurate for localization of the IA Canal. Osteotomies were made using a surgical headpiece with careful detection of the IA Canal. Drilling was along the trajectory of nerve and directed posteriorly under cooling. At completion of drilling, the cortical bone distal to the foramen was raised and removed using a chisel.

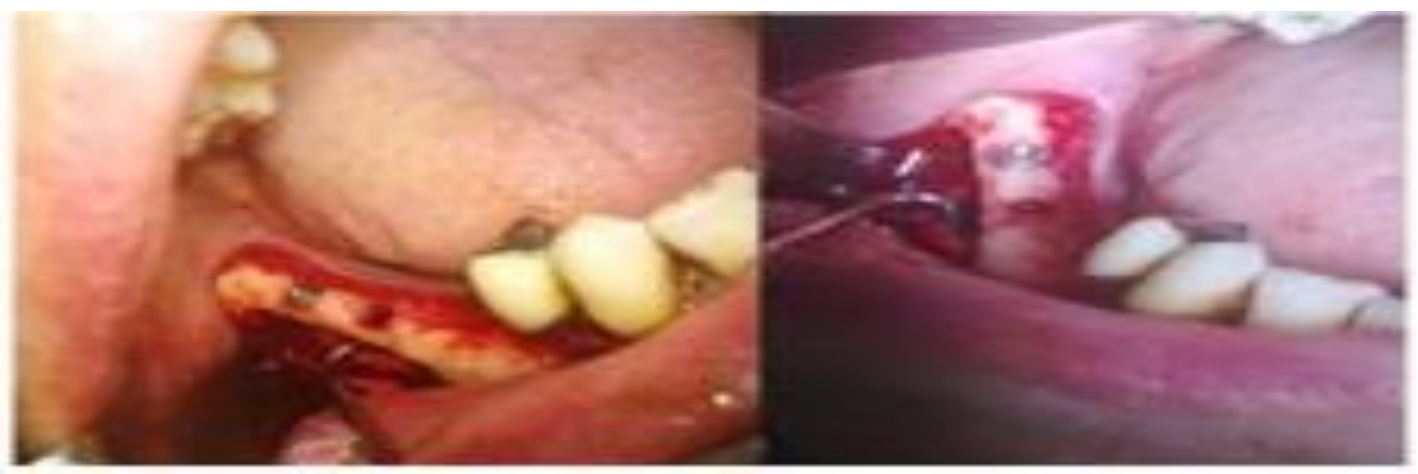

Figure 4: Surgical approach not involve the mental nerve 
IAN manipulation: After creation of bony window, the nerve was carefully released and removed from the canal using a small blunt hook. Then, the nerve was pulled laterally using gentle force by a thin tape specially made and such the nerve was kept away from the surgery site during drilling and implants insertion.

Implants placement: After lateralization of the IAN in both groups, osteotomy for implant installation was commenced. Nine Super-line Korean dental implants (Dentium Company) were used in the four patients (12-14 mm height and $3.8-4.5 \mathrm{~mm}$ in diameter). Implant insertion was carried out with care leaving the nerve aside. After insertion of implants, re-location of the inferior alveolar bundle was done. Synthetic bone substitute (chips) was packed into the osteotomy side. At completion of implant insertion, primary closure of the mucoperiosteal flap was done using 3/0 black silk suture. Regular follow-up visits were scheduled for each patient to check for any expected paresthesia or numbness.

\section{RESULTS}

Nine super-line implants were seated in their sites with a $100 \%$ success after six months observation. Paresthesia and numbness did occur in all patients and extended between 3 to 8 weeks with complete recovery after 6 months. All patients were scheduled for follow up which was for 6 years.
In group A, local anesthesia was used, while in group B, general anesthesia was preferred for easy manipulation. In both groups fixed prosthesis were delivered 6 months postsurgery. It is of importance to preserve enough bone in the buccal area of the implant, in order to guarantee sufficient primary stability. During the 6 years follow up, none of the implants failed.

\section{DISCUSSION}

During implant dentistry surgeons may be confronted with complications. The most serious complication is inferior alveolar nerve injury. Implant system, surgical technique, surgeon skills and knowledge of anatomical land marks is important in reducing such complications ${ }^{(14)}$. Placement of dental implants in a resorbed posterior mandible were vertical height is diminished or superior position of the crest is an obstacle for surgeries ${ }^{(15)}$. Onlay block graft $(16,17)$, guided bone regeneration $^{(18)}$ and nerve transposition ${ }^{(19,20)}$ are considered as added strategies to overcome reduced vertical height. The choice of proper technique to be used appears to be based on the surgeons experience rather than on compelling evidence for efficacy. Yet a dimensional change at the crest of alveolar ridge with entire graft resorption is considered as important drawback complications for block onlay grafting ${ }^{(21)}$. The incidence of nerve 
injury in implant surgery is described by various authors. According to R. Bourtling et al. ${ }^{(22)}$,only $8,5 \%$ of IAN injury cases occur during the course of dental implantation; meanwhile, J. Kan et al. ${ }^{(23)}$ claimed that on an average, $52,4 \%$ of patients suffer from neuro-sensory troubles following dental implantation. In case of certain implantation methods, these numbers amount even to 77,8 $\%$ (24). Following a complete disclosure between surgeon and patient on surgery and its possible postoperative outcomes, patients preferred nerve translocation over ridge augmentation as they considered the latter procedure being a lengthy procedure with a waiting period of (4-6) months for healing of bone graft, followed by 3-4 months for the osseo-integration period of dental implant. In addition, potential resorption of the entire graft can also be a cause for preference of nerve lateralization than ridge augmentation.

Biomechanically, IAN transposition increases occlusal force resistance with good proportion between the implant and the prosthesis ${ }^{(25)}$. In comparison between reconstruction with grafts and ridge augmentation, nerve transposition does not require donor areas so relatively it's a simple less invasive procedure, could be performed under LA, low morbidity, stable results and in addition, its lower cost ${ }^{(26,27)}$ Anatomical knowledge of the IA canal is mandatory in order to plan a proper dental implantation method. It is extremely important to detect the position of the inferior border of mandible in connection with the side compact lamellae. The canal stretches through-out the mandibular body forming an " $\mathrm{S}$ " shape curve. It stretches forwards to the front part and comes close to the vestibular surface ${ }^{(28)}$. Next to the $1^{\text {st }}$ and $2^{\text {nd }}$ molars, the longest distance between the canal and mandibular vestibular surface is up to $5 \mathrm{~mm}{ }^{(29)}$. The techniques described carry with them the risk of temporary or even permanent nerve damage, which may lead to anesthesia, hypoesthesia or paresthesia. Several studies have evaluated this risk. Mucoperiosteal flap traction by a spatula is considered the most well-known causes of inferior alveolar nerve damage ${ }^{(5,6)}$. There are two operative approaches cited in literature that suggest how to change the route of the nerve, and how to make implantation possible (depending on involvement of the mental nerve in the bony window). Although the cases are just four with nine implants we noticed that patients prefer surgeries under general anesthesia. In the postoperative period of both techniques, swelling occurred, no pain was experienced, and paresthesia extend around one week with the peak of the condition reducing and completely relieved after 6 months, all these recorded through periodic follow up intervals. Both techniques made dental implant placement feasible in position of lower premolar and molar without damaging the nerve. For patient co-operation 
LA was best, coupled with avoidance of unwanted side effects of GA agents. On the other hand, an easy, comfortable work field and less operative time were achieved under GA. In a systematic review by Boris ${ }^{(1)}$, he stated that the most popular surgical technique for IAN repositioning was IANT $(51.44 \%)$ of all operations performed utilized IANT, and 48.56\% utilized IANL with different implant survival rate (success) ranged from $100 \%$ to $33.3 \%$. In a study by Lorean et al., study implant survival rate was $99.57 \%$, by Chrcanovic et al. was $88 \%$, by Ferrigno et al. it was $95.7 \%$, by Kan et al. was a $93.8 \%$ implant survival rate. The lowest implant survival rates were found in the study by Kan et al. with $33.33 \%$ and Karlis et al. with $0 \%$. In a case report by Angélica, the two techniques showed similar sensory feedback. The authors found that the implant success rate is linked to the possibility of installing implants with long bicortical anchor, which favors primary stability and biomechanics ${ }^{(4)}$.

In the current conducted study, all 9 implants were functioning accurately with no complications occurring in the six year follow up period. Smita and Sercan Kucukkurt ${ }^{(30,31)}$ showed that implant-based rehabilitation of edentulous mandibular posterior sectors with IAN repositioning is a valid management option in cases with insufficient bone height. Mukund Rathod ${ }^{(5)}$ advises that the incidence of neurosensory disturbances may be further minimized by advances in surgical expertise and improved instrumentation.

\section{CONCLUSIONS}

Inferior alveolar nerve (IAN) Lateralization and Transposition is the most appropriate choice for dental implant replacement in atrophied posterior mandible rather than bone augmentation or using short dental implants. Skill, precision and experience must be available in the surgeon for optimal and long term success results. Permanent injury to the IAN during surgery should be avoided by carrying out a thorough clinical and radiographical examination. Patient choice for local or general anesthesia has no effect on surgeries itself.

\section{Acknowledgments}

Great appreciation and thanks to the Scientific Committee in Nineveh Health Directory.

\section{Grateful to all of Surgical} Assistant Staff for the help to perform smooth surgeries.

\section{REFERENCES}

1. Boris Abayev, Gintaras Juodzbalys. Inferior Alveolar Nerve Lateralization and Transposition for Dental Implant Placement. Part I: a Systematic Review of Surgical 
Techniques. J Oral Maxillofac Res 2015 (Jan-Mar) | vol. 6 | No 1 | e2 | p.1

2. Dr. Bernd Quantius. Lateralization of the inferior alveolar nerve. Germany Implant 3, 2010. P.18-21.

3. H. Mahmood- Hashemi. A modified technique of inferior alveolar nerve repositioning: results in 11 patients. Acta Medica Iranica, Vol. 44, No. 4 (2006) 272277.

4. Angélica Castro Pimentel, Marco Antonio Sanches, Gabriel Cardoso Ramalho, Caio Vinicius Roman-Torres, Marcello Roberto Manzi, and Wilson Roberto Sendyk. Lateralization Technique and Inferior Alveolar Nerve Transposition. Hindawi Publishing Corporation. Case Reports in Dentistry Volume 2016, Article ID 4802637.

5. Mukund Rathod. Rajesh Ashok. Samir Joshi. Sudhir Pawar. Vishal Tapadiya. Suman Gupta. Vrushika Mahajan. Evaluation of Neurosensory Function Following Inferior Alveolar Nerve Lateralization for Implant Placement. J. Maxillofac. Oral Surg. (Apr-June 2019) 18(2):273-279.

6. Boris Abayev, Gintaras Juodzbalys. Inferior Alveolar Nerve Lateralization and Transposition for Dental Implant Placement. Part II: a Systematic Review of Neurosensory Complications. J Oral Maxillofac Res 2015;6(1):e3
7. Epker BN, Wolford LM. Dentofacial deformities surgical-orthodontic correction. St. Lous: Mosby Company; 1980. p. 172.

8. Bell WH. Modern practice in orthognathic and reconstructive surgery. Philadelphia: W.B. Saunders Company; 1992. p. 2500.

9. Peterson SJ, Indresano AT, Marciani RD, Roser SM. Principles of oral and maxillofacial surgery. Philadelphia: Lippincott Company; 1992. p. 1113.

10. Jensen O, Nock D. Inferior alveolar nerve repositioning in conjunction with placement of osseointegrated implants: a case report. Oral Surg Oral Med Oral Pathol. 1987 Mar; 63(3):263-268.

11. Friberg B, Ivanoff CJ, Lekholm U. Inferior alveolar nerve transposition in combination with Branemark implant treatment. Int $\mathbf{J}$ Periodontics Restorative Dent. 1992; 12(6):440-449.

12. Perterson LJ, Indresano AT, Marciani RD, Roser SM. Principles of oral and maxillofacial surgery. Philadelphia: Lippincott Company; 1992. p. 1072.

13. De Vicente JC, Lopez-Arranz JS. Preservation of the inferior alveolar nerve in the surgical approach to cancer of the posterior oral cavity. J Oral Maxillofac Surg. 1998 Oct; 56(10):1214-1216.

14. Juliano D. et al. Inferior alveolar nerve transposition with involvement of the mental foramen for implant placement. 
Med Oral Patol Oral Cir Buccal. Nove.2008.1;13(11) E722-5.

15. Ahmed Ali Alhassani, Ali Saad Thafeed AlGhamdi.: Inferior Alveolar Nerve Injury in Implant Dentistry: Diagnosis, Causes, Prevention and Management. J Oral Implantol, 400-406.

16. Kahn A, Shlomi B, Levy Y, Better H, Chaushu G: The use of autogenous block graft for augmentation of the atrophic alveolar ridge. Refuat Hapeh Vehashinayim 20:3, 54, 102, 2003.

17. Proussaefs P, Lozada J, Kleinman A, Roher MD: The use of ramus autogenous block graft for vertical alveolar ridge augmentation and implant placement: A pilot study. Int J Oral Maxillofac Implants 17:2, 238, 2002

18. Simon BI, et al. Changes in alveolar bone height and width following ridge augmentation using bone graft. J Periodontal $71: 11,1774,2000$

19. Rosenquist B: Implant placement in combination with nerve transpositioning. Int J Oral Maxillofac Implants 9:522, 1994

20. Ole T. Jensen. Alveolar Segmental "Sandwich" Osteotomies for Posterior Edentulous Mandibular Sites for Dental Implants. AAOMS, 2006.

21. Pikos MA: Block autografts for localized ridge augmentation. Part II. The posterior mandible. Implant Dent 9:1, 67, 2000

22. Bartling R, Freeman K, Kraut RA. The incidence of altered sensation of the mental nerve after mandibular implant placement. J Oral Maxillofac Surg 1999; 57(12):1408-12.

23. Kan JY, et al. Endosseous implant placement in conjunction with inferior alveolar nerve transposition. Int $\mathbf{J}$ Oral Maxillofac Implants 1997; 12(4): 46371.

24. Ricardas K. et al .Traumatic Damage to the Inferior Alveolar Nerve Sustained in Course of Dental Implantation. Possibility of Prevention. Baltic Dental and Maxillofacial Journal, 6:106-10, 2004.

25. Sethi A. Inferior alveolar nerve repositioning in implant dentistry: a preliminary report. Int $\mathrm{J}$ Periodontics Restorative Dent. 1995. Oct;15(5):474-81.

26. Rosenquist B. Implant placement posterior to the mental foramen with transpositioning of the inferior alveolar nerve. Int J Oral Maxillofac Implants. 1992 Spring; 7(1):45-50.

27. Dario LJ, English R Jr. Achieving implant reconstruction through bilateral mandibular nerve repositioning. J Am Dent Assoc. 1994 Mar; 125(3):305-9.

28. Howard Davis W. Mobilization of the Alveolar Nerve to Allow Placement of Osseointegratible Implants. In: Advanced Osseointegration Surgery: Application in the Maxillofacial Region. Quintessence Publishing Co Ltd; 2000.

29. Hirsch JM, Branemark PI. Implant Stability and Nerve Function after 
Transposition and Lateralization of the Inferior Nerve Implant Installation. $\mathrm{Br} \quad \mathrm{J}$ Oral Maxillofacial Surg 1995; 33(5): 276-81.

30. Smita Iqbal Musani, Umang Deepak Shah, Ramandeep Dugal, Deepak Kaul Transposition of inferior alveolar nerve with simultaneous implant replacement CASE REPORT ( Journal of Dental
Implant ). 2016. Volume 6. Issue 1. page 41-43.

31. Öğr. Üyesi Sercan. Tuğçe BĠÇER AYTUĞAR. Inferior Alveolar Nerve Transposition in Conjunction with Dental Implant Placement. J Dent Fac Atatürk Uni. March 2019. Cilt: 29, Say1: 2, Y11: 2019, Sayfa, 306-312. 